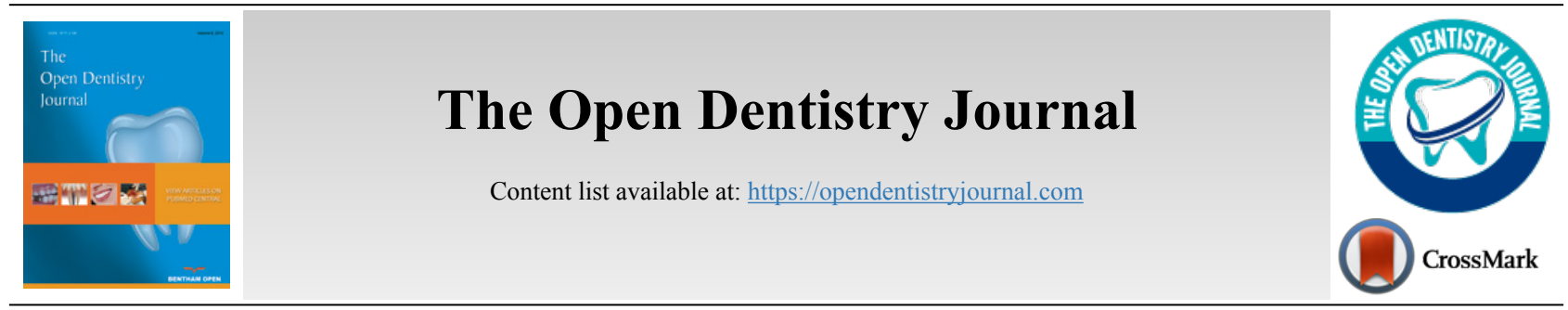

$\left({ }^{\prime}, 725, \$ /\right.$

\title{
Recommendations and Management in Dental Practice during Corona Virus COVID-19
}

\author{
Kanwar Deep Singh Nanda, and Jasmine Nanda ${ }^{2}$ \\ ${ }^{I}$ Department of Oral and Maxillofacial Pathology, Dr. Nanda's Multi-specialty Dental Care, New Delhi, India \\ ${ }^{2}$ Department of Pediatric Dentistry, Inderprastha Dental College, Ghaziabad, Uttar Pradesh, India
}

The outbreak of novel coronavirus (2019-nCoV) pneumonia initially developed in one of the largest cities, Wuhan, in Hubei province of China last December and have become a major challenging public health problem for not only China but also countries around the world [1]. On January 30, 2020, the World Health Organization (WHO) announced that this outbreak had constituted a public health emergency of international concern [2]. The novel coronavirus was initially named 2019-nCoV and officially as severe acute respiratory syndrome coronavirus (SARSCoV-2). As of February 26, COVID-19 has been recognized in 34 countries, with a total of 80,239 laboratory-confirmed cases and 2,700 deaths [3].

This article, based on our experience and relevant guidelines and research, to introduces the essential knowledge about COVID-19 infection in dental settings and provides recommendations and management protocols for dental practitioners and students in (potentially) affected areas.

\section{ETIOLOGY}

Coronaviruses are enveloped non-segmented positivesense RNA viruses belonging to the family Coronaviridae and the order Nidovirales and broadly distributed in humans and other mammals similar to SARS-CoV and Middle East Respiratory Syndrome coronavirus (MERS-CoV). SARSCoV-2 is zoonotic, with Chinese horseshoe bats (Rhinolophus sinicus) being the most probable origin $[4,5]$.

\section{MODE OF TRANSMISSION}

Based on genetic and epidemiologic research, it has been found that the COVID-19 outbreak started with a single animal-to-human transmission, which later followed human-tohuman spread [4]. It is now believed that its interpersonal

\footnotetext{
* Address correspondence to this author at the Department of Oral and Maxillofacial Pathology, Dr. Nanda's Multispeciality Dental Care, 9A/1, East Patel Nagar, $\mathbb{N}$ New Delhi, India; Tel: +91-9650122662;

E-mail:kdsnanda@gmail.com
}

transmission occurs mainly via respiratory droplets and contact transmission [6]. Recent study has found COVID19 in the saliva of infected patients [7]. The COVID-19 outbreak is a reminder that all dental and other health professionals must always be diligent in protecting against the spread of infectious disease. It has been observed in one study that asymptomatic patients and patients in their incubation period are also carriers of SARS-CoV-2 [4].

\section{INCUBATION PERIOD}

5 to 6 days is the estimated incubation period of COVID-19, but there is evidence that it could be as long as 14 days, which is now the commonly adopted duration for medical observation and quarantine of (potentially) exposed persons [8].

\section{FATALITY RATE}

According to current data, the fatality rate (cumulative deaths divided by cumulative cases) of COVID- 19 is $0.39 \%$ to $4.05 \%$, which is lower than that of SARS (severe acute respiratory syndrome; $\approx 10 \%$ ) and MERS (Middle East respiratory syndrome; $\approx 34 \%[9]$.

\section{HIGH RISK OF INFECTION}

People of all ages are generally susceptible to this new infectious disease. But those who are in close contact with patients with symptomatic and asymptomatic COVID-19, including health care workers and other patients in the hospital, are at higher risk of SARS-CoV-2 infection. In an analysis of 138 hospitalized patients with COVID-19 in Wuhan, 57 (41\%) were presumed to have been infected in hospital, including 40 $(29 \%)$ health care workers and $17(12 \%)$ patients hospitalized for other reasons [10].

\section{CLINICAL FEATURES}

The coronavirus infection in humans frequently presents 
with mild severity which includes fever, cough, and acute respiratory disease. Other atypical symptoms include muscle pain, confusion, headache, sore throat, diarrhea, and vomiting [1]. However, severe cases lead to pneumonia, kidney failure or even death [10]. In general, older age and the existence of underlying comorbidities (e.g., diabetes, hypertension, and cardiovascular disease) were associated with poorer prognosis $[4,6]$.

\section{DIAGNOSIS}

The diagnosis of COVID-19 can be based on a combination of epidemiologic information (e.g., a history of travel to or residence in affected region of 14 days prior to symptom onset), clinical symptoms, CT imaging findings, and laboratory tests (e.g., reverse transcriptase polymerase chain reaction [RT-PCR] tests on respiratory tract specimens). It has been observed that a single negative RT-PCR test result from suspected patients does not exclude infection. Clinically, we should be alert of patients with an epidemiologic history, COVID-19-related symptoms, and/or positive CT imaging results [10].

\section{RECOMMENDATIONS AND PRECAUTIONS FOR DENTAL PRACTICE}

COVID19 has been put under the category of group B infectious diseases and all health care workers have been advised to use protection measures reserved for extremely infectious pathogens,

[a] All routine dental procedures that can produce aerosol or droplet should be suspended till the time respective government has announced lockdown. It is safe to advise prescription to patients on phone or online guiding them.

[b] A detailed history of patient who has history of recent travel to any epidemic regions or has been quarantine for 14 days along with fever, cough, sneezing, or COVID-19 related symptoms or contact with a close family member who is confirmed with the infection is advised to undergo a medical examination in a designated hospital.

[c] Patients and their accompanying persons are provided with medical masks, hand sanitizer and temperature measurement once they enter dental hospital. If found any COVID 19 symptoms should immediately be referred to designated hospitals

[d] It is recommended to record the temperature of every auxiliary staff and doctor as a routine procedure.

[e] In case of emergency procedure following precautions should be taken care

[i] Hand hygiene is considered the most critical measure for reducing the risk of transmission.

[ii] The use of personal protective equipment, including masks (e.g., N-95 masks authenticated by the National Institute for Occupational Safety and Health), gloves, gowns, and goggles or face shields are recommended to protect skin and mucosa from (potentially) infected blood or secretions during routine dental practice

[iii] Use of rubber dams or high-volume saliva ejectors can reduce the production of droplets and aerosols. Further use of preoperative antimicrobial mouth rinse with $0.2 \%$ povidone-iodine could reduce the number of microbes in the oral cavity.

[iv] Aerosol-generating procedures, such as the use of a 3-way syringe, ultrasonic instruments and highspeed handpiece should be minimized as much as possible. Use of disposable (single use) devices such as mouth mirror, syringes and blood pressure cuff to prevent crosscontamination.

[v] Intraoral periapical radiograph (IOPAR) examination is the most common procedure which sometimes can stimulate saliva secretions and coughing. This can be minimized by extraoral dental radiographies, such as panoramic Orthopantomogram (OPG) or cone beam CT (CBCT).

[vi] Chemo-mechanical (pulp devitalization) caries removal under rubber dam with high volume saliva ejector after local anesthesia can be done in case of symptomatic irreversible pulpitis to reduce the pain.

[vii] In case of tooth extraction, absorbable suture is preferred. Patients with facial soft tissue contusion, debridement and suturing should be performed. It is recommended to rinse the wound slowly and use the saliva ejector to avoid spraying.

[viii] Life-threatening cases with oral and maxillofacial fractures or injuries should be admitted to the hospital immediately, and a precautionary chest $\mathrm{CT}$ should be done if available to exclude suspected infection because the RT-PCR test, is time-consuming and need a laboratory with pan-coronavirus or specific SARS-CoV-2 detection capacity.

[ix] Human coronavirus can survive on inanimate surfaces up to 9 days at room temperature. Therefore, after every patient treatment, environmental cleaning and disinfection procedures by chemicals approved for COVID-19 is mandatory. Alternatively, patients could be treated in an isolated and well-ventilated room or negatively pressured rooms if available for suspected cases with COVID-19.

\section{CONCLUSION}

Currently, the approach to COVID-19 is to control the source of infection. Prevention and control measures like hand hygiene, protective equipment and respiratory hygiene should be updated in all dental clinics. Early diagnosis by quick pathogen tests, isolation, and supportive care for affected patients can lower the risk of transmission. 


\section{REFERENCES}

[1] Phelan AL, Katz R, Gostin LO. The novel coronavirus originating in Wuhan, China: challenges for global health governance. JAMA 2020; 323(8): 709-10.

[http://dx.doi.org/10.1001/jama.2020.1097] [PMID: 31999307]

[2] Mahase E. China coronavirus: WHO declares international emergency as death toll exceeds 200. BMJ 2020; 368: $\mathrm{m} 408$. [http://dx.doi.org/10.1136/bmj.m408] [PMID: 32005727]

[3] Coronavirus disease. Situation Report - 35. accessed 2020 Feb 262019. Available from: https://www.who.int/ docs/default-source/corona viruse/situation-reports/20200224-sitrep-35covid-19.pdf?sfvrsn=1ac4218d_2

[4] Chen N, Zhou M, Dong X, et al. Epidemiological and clinical characteristics of 99 cases of 2019 novel coronavirus pneumonia in Wuhan, China: A descriptive study. Lancet 2020; 395(10223): 507-13. [http://dx.doi.org/10.1016/S0140-6736(20)30211-7] [PMID: 32007143]

[5] Lu R, Zhao X, Li J, et al. Genomic characterisation and epidemiology of 2019 novel coronavirus: Implications for virus origins and receptor binding. Lancet 2020; 395(10224): 565-74.

[http://dx.doi.org/10.1016/S0140-6736(20)30251-8] [PMID: 32007145]
[6] Huang C, Wang Y, Li X, et al. Clinical features of patients infected with 2019 novel coronavirus in Wuhan, China. Lancet 2020; 395(10223): 497-506

[http://dx.doi.org/10.1016/S0140-6736(20)30183-5] [PMID: 31986264]

[7] Sabino-Silva R, Jardim ACG, Siqueira WL. Coronavirus COVID-19 impacts to dentistry and potential salivary diagnosis. Clin Oral Investig 2020; 24(4): 1619-21.

[http://dx.doi.org/10.1007/s00784-020-03248-x] [PMID: 32078048]

[8] Backer JA, Klinkenberg D, Wallinga J. Incubation period of 2019 novel coronavirus $(2019-\mathrm{nCoV})$ infections among travellers from Wuhan, China, 20-28 January 2020. Euro Surveill 2020; 25(5)2000062

[http://dx.doi.org/10.2807/1560-7917.ES.2020.25.5.2000062] [PMID: 32046819]

[9] Malik YS, Sircar S, Bhat S, et al. Emerging novel coronavirus (2019$\mathrm{nCoV}$ )-current scenario, evolutionary perspective based on genome analysis and recent developments. Vet Q 2020; 40(1): 68-76. [http://dx.doi.org/10.1080/01652176.2020.1727993]

[PMID: 32036774]

[10] Wang D, Hu B, Hu C, et al. Clinical characteristics of 138 hospitalized patients with 2019 novel coronavirus-infected pneumonia in Wuhan, China. JAMA 2020; 323(11): 1061-9.

[http://dx.doi.org/10.1001/jama.2020.1585] [PMID: 32031570]

\section{(C) 2020 Nanda and Nanda.}

This is an open access article distributed under the terms of the Creative Commons Attribution 4.0 International Public License (CC-BY 4.0), a copy of which is available at: (https://creativecommons.org/licenses/by/4.0/legalcode). This license permits unrestricted use, distribution, and reproduction in any medium, provided the original author and source are credited. 